Anatomía

\title{
Anatomía comparativa de raíz, tallo, hoja y base del pedúnculo de Manfreda (Asparagaceae: Agavoideae)
}

\author{
Comparative anatomy of the stem, leaf, and inflorescence basal axis of Manfreda (Asparagaceae: \\ Agavoideae) \\ Eloy Solano $^{\mathrm{a}}$, Teresa Terrazas ${ }^{\mathrm{b}, *}$, Jorge Reyes-Rivera ${ }^{\mathrm{a}}$ y Héctor Serrano-Casas ${ }^{\mathrm{a}}$ \\ ${ }^{a}$ Unidad de Investigación en Sistemática Vegetal y Suelo, Facultad de Estudios Superiores Zaragoza, Universidad Nacional Autónoma de México, Batalla 5 \\ de mayo s/n, Col. Ejército de Oriente, Iztapalapa, 09230 Ciudad de México, México \\ ${ }^{\mathrm{b}}$ Instituto de Biología, Universidad Nacional Autónoma de México, Apartado postal 70-633, Ciudad Universitaria, 04510 Ciudad de México, México
}

Recibido el 6 de julio de 2016; aceptado el 3 de mayo de 2017

Disponible en Internet el 21 de noviembre de 2017

\begin{abstract}
Resumen
Se estudió comparativamente la anatomía vegetativa de 13 especies de Manfreda. Las muestras recolectadas en el campo fueron procesadas con la técnica de inclusión en parafina. Todas las especies presentan raíces contráctiles y fibrosas, algunas con células internas lignificadas formando una banda de 1-5 estratos. Manfreda nanchititlensis se caracteriza por tener células endodérmicas engrosadas. El cormo presenta un meristemo secundario de engrosamiento y algunas especies tienen cuerpos de sílice en el parénquima de este órgano. Este rasgo es raro en el cormo de las monocotiledóneas y es el segundo registro de cuerpos de sílice en el cormo de las Asparagales. El bulbo presenta un meristemo primario de engrosamiento cerca de la base de las hojas. La base del pedúnculo tiene una banda de esclerénquima, rafidios y estiloides presentes o ausentes en el parénquima. Las láminas foliares se caracterizan por tener estomas paracíticos, son unifaciales con parénquima esponjoso. Tricomas y una peridermis continua en la superficie abaxial distinguen a Manfreda pubescens; este tejido también se presenta en Manfreda maculata pero de forma discontinua. Una vaina de parénquima con escasos estiloides rodea los haces vasculares de Manfreda pringlei. Las características anatómicas descritas en combinación con otras evidencias contribuyen a la sistemática del género Manfreda.
\end{abstract}

(C) 2017 Universidad Nacional Autónoma de México, Instituto de Biología. Este es un artículo Open Access bajo la licencia CC BY-NC-ND (http://creativecommons.org/licenses/by-nc-nd/4.0/).

Palabras clave: Cuerpos de sílice; Estiloides; Meristemo de engrosamiento secundario; Raíz contráctil

\section{Abstract}

The vegetative anatomy of 13 species of Manfreda was studied. The samples collected in the field were prepared by the paraffin embedding technique. All species have contractile and fibrous roots, some of them having a band of 1-5 strata of lignified internal cells. Manfreda nanchititlensis has a thick-walled endodermis. The corm has a secondary thickening meristem and some species possess silica bodies in the parenchyma of this organ. This trait is rare in the corms of monocots and it is the second record of silica bodies in the corms in Asparagales. The bulb has a primary thickening meristem near the base of the leaves. The base of the peduncle has a band of sclerenchyma and raphides and styloids present or absent in the parenchyma. The leaf blades have paracitic stomata, they are unifacial with spongy parenchyma. Trichomes and a continuous abaxial periderm distinguish Manfreda pubescens, whereas a discontinuous periderm is distinctive of Manfreda maculata. A parenchyma bundle sheath with few styloids distinguishes Manfreda pringlei. The anatomical features described in combination with other evidence contribute to the systematics of Manfreda.

(C) 2017 Universidad Nacional Autónoma de México, Instituto de Biología. This is an open access article under the CC BY-NC-ND license (http://creativecommons.org/licenses/by-nc-nd/4.0/).

Keywords: Silica bodies; Styloids; Secondary thickening meristem; Contractile root

\footnotetext{
* Autor para correspondencia.

Correo electrónico: tterrazas@ib.unam.mx (T. Terrazas).

La revisión por pares es responsabilidad de la Universidad Nacional Autónoma de México.
} 


\section{Introducción}

El género Manfreda pertenece a la familia Asparagaceae, subfamilia Agavoideae (APG III, 2009). Se distribuye desde el sureste de los EUA, hasta el norte de Nicaragua. México es el centro de diversidad del género. De las 32 especies reconocidas, $31(97 \%)$ son propias de este país (Castillejos, 2009), la mayoría consideradas como microendemismos, debido a que ocupan menos del 1.5\% del territorio nacional (García-Mendoza, 1995).

Las manfredas son plantas herbáceas, perennes, caducifolias, acaulescentes, con rizomas, cormos y bulbos, los bulbillos son raros; hojas en roseta, lineares, lanceoladas $\mathrm{u}$ oblanceoladas, verde brillantes o verde glaucas, a veces con máculas; inflorescencia en espiga, flores tubulares, campanuladas, infundibuliformes a hipocrateriformes, solitarias, perianto usualmente de color verde, a veces con tintes rojos, blancos, amarillos, pardos, rosados o guindas; tépalos en 2 series, oblongos, extendidos o revolutos, rara vez erectos, 6 estambres, exertos; ovario ínfero, trilocular; fruto una cápsula globosa u oblonga con dehiscencia loculicida; semillas planas, más o menos deltoides, de color negro (Castillejos, 2009). La mayoría de las especies de este género tiene potencial ornamental, otras se usan con fines medicinales, y por su alta concentración de sapogeninas en sus cormos y bulbos; han sido utilizadas desde la época prehispánica como sustituto del jabón (Nobel, 1998; Piña, 1985; Verhoek-Williams, 1975).

El número de especies de Manfreda ha variado en función de los criterios utilizados para separarlas. Por ejemplo, Rose (1899) reconoció 17 y Castillejos (2009) 32. Los caracteres anatómicos no han sido utilizados en la delimitación de las especies de este género, debido a que no se han realizado estudios de este tipo que involucren a la mayoría de los taxones y sus órganos.

En 6 géneros de Asparagales sensu APG III (2009) se han realizado estudios sobre la anatomía de las raíces (Claus, 1954; Fritsch, 1992; Pant, 1943; Schlittler, 1951). También ha sido descrita la anatomía de la raíz en Asteliaceae, Behniaceae, Blandfordiaceae, Iridaceae e Hypoxidaceae (Conran, 1999; Rudall, 1995; Rudall, Chase, Cutler, Rusby y de Bruijn, 1998). Tomlinson y Zimmermann (1969) observaron que la raíz de Dracaena es la única monocotiledónea donde el meristemo de engrosamiento secundario (MES) se prolonga hasta la misma. Kauff, Rudall y Conran (2000) estudiaron la anatomía de este órgano en un contexto sistemático del orden Asparagales y otras monocotiledóneas.

Sobre la base de la actividad del meristemo de engrosamiento primario (MEP) y el MES, Mangin (1882) dividió las monocotiledóneas en 4 grupos. Ubicó el género Agave en el segundo grupo debido a su hábito herbáceo y MEP activo después de la formación de raíces, mientras que Yucca, Dracaena y Cordyline los incluyó en un tercer grupo por ser arborescentes y presentar MES. Chakraverti (1939) indicó que el bulbo (cormo) de Polianthes tuberosa presenta un MES menos desarrollado que el tallo aéreo de Dracaena. Solano, Terrazas y González-Becerril (2013) también señalaron la presencia de MES en el cormo del género Polianthes y en 4 especies registraron, por primera vez para el orden Asparagales, cuerpos de sílice en este órgano.
Tabla 1

Especies de Manfreda estudiadas y su recolector.

M. elongata Rose, R. Ríos G. 135, C. Castillejos 1519; M. galvanie

A. Castañeda, S. Franco y García-Mend., E. Solano C. 1582, 1773;

M. guerrerensis Matuda, E. Solano C. 1756; M. guttata (Jacoboi y

Buoché) Rose, Castillejos 1384, E. Solano C. 1538; M. hauniensis

(J. B. Petersen) Verh.-Will., Castillejos 1743;

M. longiflora (Rose) Verh.-Will., E. Solano C. 1657B;

M. longiflora (Rose) Verh.-Will., E. Solano C. 1657B;

M. maculata (C. Mart.) Rose, E. Solano C. 1657B;

M. nanchititlensis Matuda, E. Solano C. 1665, 1665B; M. potosina

(B. L. Rob. y Greenm.) Rose, C. Castillejos. 1159, E. Solano C.

1553; M. pringlei Rose, E. Solano C. 1637, C. Castillejos 1490,

C. Castillejos 1111; M. pubescens (Regel y Ortgies) Verh.-Will. ex

Pina, R. Ríos 223B, C. Castillejos 1470, E. Solano C. 1711;

M. scabra (Regel y Ortgies) Verh.-Will. ex Espejo y López-Ferrari,

C. Castillejos 1559, 1576, 1572, E. Solano C. 1669, 1620, 1723;

M. singuliflora (S. Watson) Rose, C. Castillejos 1357

Los ejemplares de herbario están depositados en FEZA y MEXU.

Álvarez $(1985,1990)$ estudió la epidermis de la hoja en Agavaceae y corroboró la clasificación genérica de las 4 tribus que conforman esta familia sensu Dahlgren, Clifford y Yeo (1985). La anatomía foliar comparada, además de evidencias moleculares del clado-Trichocentrum (Orchidaceae), fue analizada por Cetzal-Ix, Noguera-Savelli, Jáuregui y Carnevali (2013), quienes concluyeron que las hojas unifaciales y las inclusiones epidérmicas son sinapomorfias de Cohniella y respaldan la monofilia de este clado. Solano et al. (2013) indicaron que en la hoja de Polianthes hay evidencias anatómicas que permiten separar algunas especies. Gutiérrez, Salgado, Grego-Valencia y Terrazas (2015) estudiaron la anatomía foliar del complejo Milla, conformado por los géneros Bessera, Dandya, Milla y Petronymphe, y registraron que Bessera tiene las paredes de las células epidérmicas colenquimatosas y el metaxilema en forma de «T»; los otros géneros carecen de caracteres foliares distintivos. En el presente estudio se analiza la anatomía de 13 especies de Manfreda, con la intención de evaluar y registrar evidencias con posible valor sistemático.

\section{Materiales y métodos}

Se recolectaron individuos completos de 13 especies de Manfreda en su área de distribución en México (tabla 1). Los especímenes herborizados fueron depositados en las colecciones FEZA y MEXU. De 1 a 3 individuos - por especie y en floración - se fijaron en una solución de formol, ácido acético glacial, alcohol etílico y agua (10:5:50:35) (Johansen, 1940) por más de $48 \mathrm{~h}$. Trascurrido este tiempo, se lavaron a chorro de agua durante varios minutos hasta eliminar el olor a formol y se almacenaron en una solución de glicerina, etanol (95\%) y agua (1:1:1) hasta que fueron seccionados. Las raíces contráctiles fueron divididas en su parte media, los cormos y los bulbos se cortaron en 3 porciones: basal, media y apical. Estas partes se seccionaron transversal y tangencialmente, con un grosor de 2-3 mm. Del mismo modo, se seccionó la base del eje de la inflorescencia. Se realizaron secciones transversales de $5 \mathrm{~mm}$ de una de las hojas 
más externas de la roseta de cada individuo. Los tejidos se ablandaron en una solución de etilen-diamina al $0.4 \%$ durante 24 a 48 h (Carlquist, 1982). Después de este tiempo, el material fue lavado a chorro de agua. Todos los tejidos fueron deshidratados en terbutanol usando un procesador de tejidos Leica TP1020 y embebidos en Histowax (Leica) a una temperatura de fusión de $56-58^{\circ} \mathrm{C}$.

Secciones transversales y longitudinales de los cormos, los bulbos, las hojas y la base del pedúnculo con un grosor de 12 a $14 \mu \mathrm{m}$ se realizaron con un micrótomo rotatorio Leica RM2125FT (Leica, Wetzlar, Alemania). Estas secciones fueron adheridas con Haupt a portaobjetos; se tiñeron con safraninaverde rápido y se montaron con resina sintética. Para describir el patrón de venación las hojas fueron aclaradas siguiendo la técnica descrita por Hickey (1973). Impresiones de las superficies adaxial y abaxial de las hojas en plantas vivas fueron realizadas con barniz para observar los estomas, una vez seco el barniz, las impresiones se montaron en un portaobjetos. Los tejidos fueron observados con un microscopio óptico Nikon, modelo Eclipse E200 (Nikon Corporation, Tokio, Japón).

\section{Resultados}

Morfología vegetativa. Todas las especies de Manfreda son hierbas caducifolias; presentan 2 tipos de tallos hipogeos: cormo y bulbo. El cormo es cilíndrico, subgloboso o de forma irregular, con entrenudos muy cortos, raíces contráctiles y fibrosas, con yemas axilares blanco amarillentas dispuestas en forma alterna espiralada, cubiertas parcial o totalmente por catáfilas pardas; los cormos generalmente carecen de bulbillos, y en algunas especies a partir de ellos se desarrollan apéndices estoloníferos. El bulbo carece de raíces, es cilíndrico, obovoide, ovoide o de forma irregular; las bases de las hojas de las estaciones anteriores de crecimiento cubren el bulbo y son de consistencia membranácea o fibrosa (fig. 1). Las hojas son anuales, alternas espiraladas, con textura foliácea, suculenta o semisuculenta, linear-lanceoladas, lanceoladas o lineares, varían de $10 \mathrm{~cm}$ hasta $1 \mathrm{~m}$ de longitud, con margen entero, hialino papiloso, denticulado o dentado, ápice agudo, redondeado y de consistencia suave, excepto en Manfreda hauniensis, donde es duro y pungente cuando la hoja se seca, las caras adaxial y abaxial generalmente son glabras y con papilas. El eje floral es terete, a veces estriado o con surcos longitudinales, las brácteas de la porción estéril son similares a las hojas y disminuyen de tamaño hacia la porción distal de la inflorescencia.

Anatomía de la raíz. En todas las especies estudiadas la exodermis ha desplazado a la epidermis. Las células de la exodermis son largas periclinalmente, por debajo de ellas, el parénquima en sección transversal tiene células de forma irregular y largas en sentido horizontal, en la parte media son grandes y largas radialmente, las cercanas a la endodermis son poliédricas y pequeñas (fig. 2A). Sólo Manfreda longiflora y Manfreda potosina tienen células poliédricas en la mayor parte del parénquima. Se observan escasos rafidios cerca de la exodermis en Manfreda guerrerensis, M. longiflora y $M$. potosina; mientras que en las demás especies están ausentes (fig. 2B). La capa de células colindantes con la endodermis puede o no formar un anillo irregular,

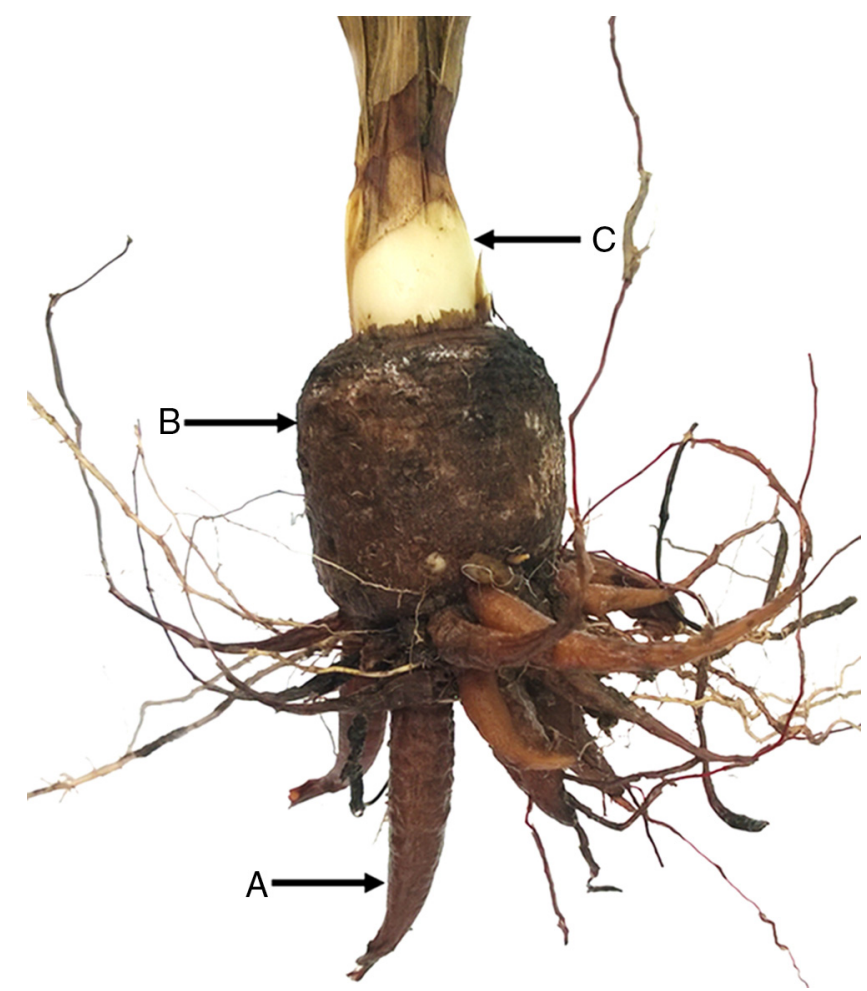

Figura 1. Manfreda pringlei: raíces contráctiles (A), cormo (B) y bulbo (C).

compuesto por 1 a 5 estratos de células con paredes engrosadas: Manfreda scabra de 1 a 2, M. guerrerensis y Manfreda singuliflora 2, Manfreda pubescens 2 a 3, Manfreda nanchititlensis 4 o 5 , respectivamente, mientras que el resto de las especies estudiadas carecen de este anillo (fig. 2C). Cabe mencionar que los estratos no son continuos, pero si se presenta uno de ellos, entonces rodea completamente a la endodermis.

En sección transversal la endodermis es uniseriada, con células rectangulares o irregulares, en general con paredes delgadas y banda de Caspary, solo en $M$. nanchititlensis las paredes tangenciales están engrosadas. El periciclo generalmente es uniseriado, únicamente en $M$. longiflora, $M$. nanchititlensis, $M$. potosina, $M$. pubescens y $M$. singuliflora es biseriado (fig. 2C y D). Las raíces de todas las especies son poliarcas. El protoxilema y el metaxilema se disponen en polos discretos acompañados de fibras y el floema se intercala (fig. 2E y F).

Anatomía del cormo. No se observó epidermis. La peridermis es unidireccional con felógeno y felema. El felógeno está conformado células de diámetro radial angosto, el felema tiene varios estratos de células, sin idioblastos, ni espacios intercelulares que se colapsan al alejarse del felógeno (fig. 3 A). Por debajo de la peridermis las células parenquimáticas son ligeramente largas horizontalmente y tienden a ser isodiamétricas conforme se aproximan al MES. En el parénquima próximo al MES y en el de la porción media del cormo se observan generalmente estiloides, rafidios y cuerpos de sílice (fig. 3B); estos últimos no se observan en $M$. hauniensis. En la tabla 2 se enlistan las especies que tienen estos idioblastos y su abundancia. En todas las especies estudiadas de Manfreda, el MES contiene haces vasculares en desarrollo, diferenciándose primero los ele- 

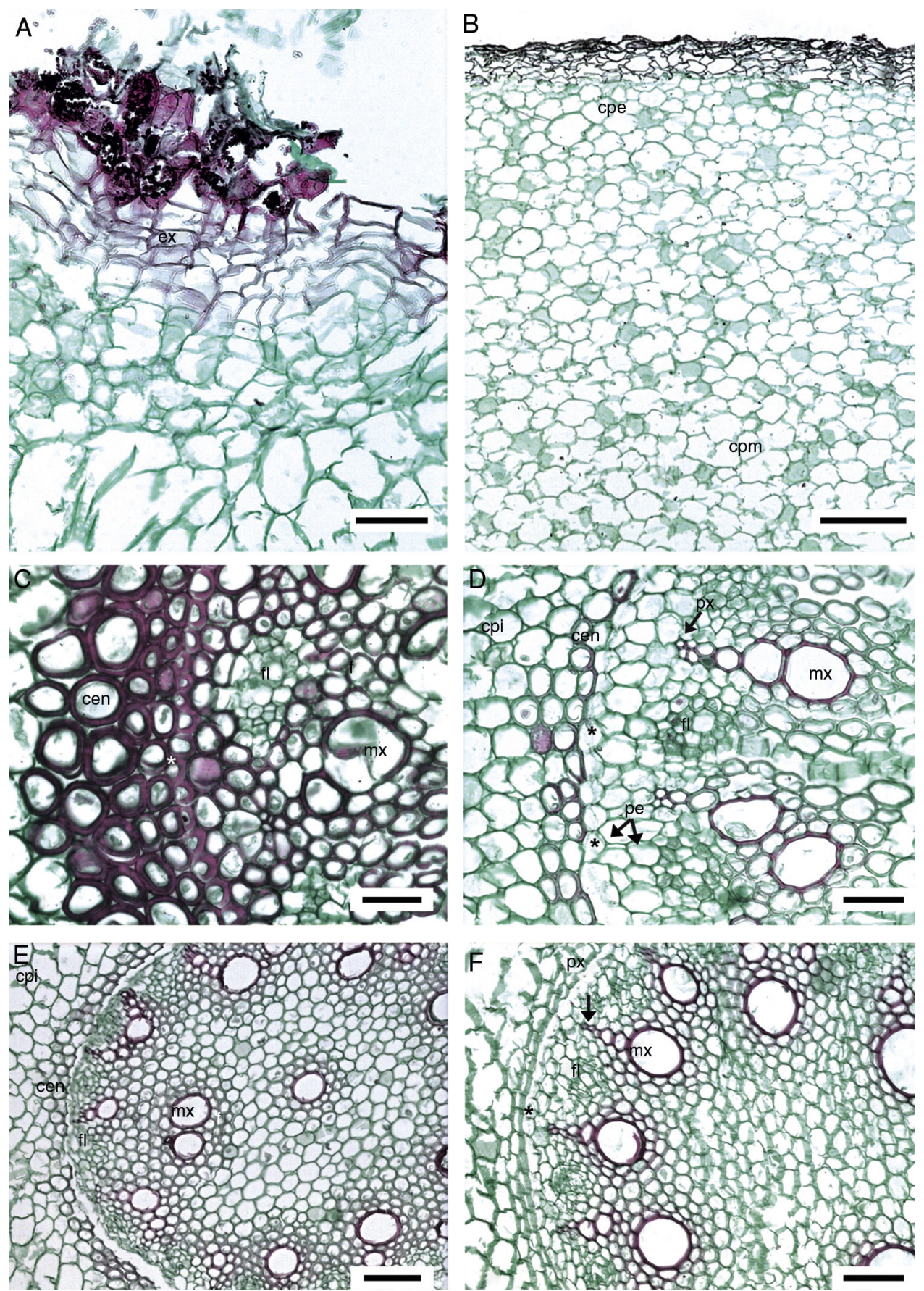

Figura 2. Raíz de Manfreda (sección transversal [ST]). A) M. guttata, vista general. B) M. potosina, células del parénquima externo e interno. C) M. nanchititlensis, 4-5 estratos de esclerénquima colindantes a la endodermis, periciclo biseriado con células lignificadas. D) M. pubescens, 3 estratos de esclerénquima colindantes ala endodermis, periciclo biseriado no lignificado. E) M. guerrerensis, protoxilema y metaxilema. F) M. pringlei, células de parénquima colindantes a la endodermis Barra es $10 \mu \mathrm{m}$ en A, $300 \mu \mathrm{m}$ en B; $50 \mu \mathrm{m}$ en C y D; $100 \mu \mathrm{m}$ en E y F. cpe: células del parénquima externas; cpi: células del parénquima internas; cpm: células del parénquima medias; cen: células cerca de endodermis; ex: exodermis; fl: floema; f: fibras; mx: metaxilema; pe: periciclo; px: protoxilema; *: endodermis.

mentos cribosos y después los traqueales. Los haces vasculares son colaterales. En el parénquima de la atactostele se observan estiloides y rafidios (fig. 3C-E).

Anatomía del bulbo. La cutícula varía de delgada a muy gruesa (tabla 3). En M. pubescens la cutícula es estriada; en las demás especies, lisa. La epidermis es uniestratificada, con células cuadradas, a veces largas verticalmente, sin contenidos minerales, con o sin protuberancias (fig. 4A y B). En $M$. potosina la epidermis forma invaginaciones en las bases foliares (fig. 4C). Por debajo de la epidermis se distingue parénquima esponjoso (fig. 4D) e idioblastos con estiloides y rafidios, distribuidos irregularmente por todo el parénquima. En las células subepidérmicas los estiloides no se observan en algunos individuos de M. elongata, M. longiflora y M. scabra, mientras que los rafidios debajo de la epidermis distinguen a $M$. pubescens (fig. 4D). Estos idioblastos en el parénquima varían en abundan- 
A
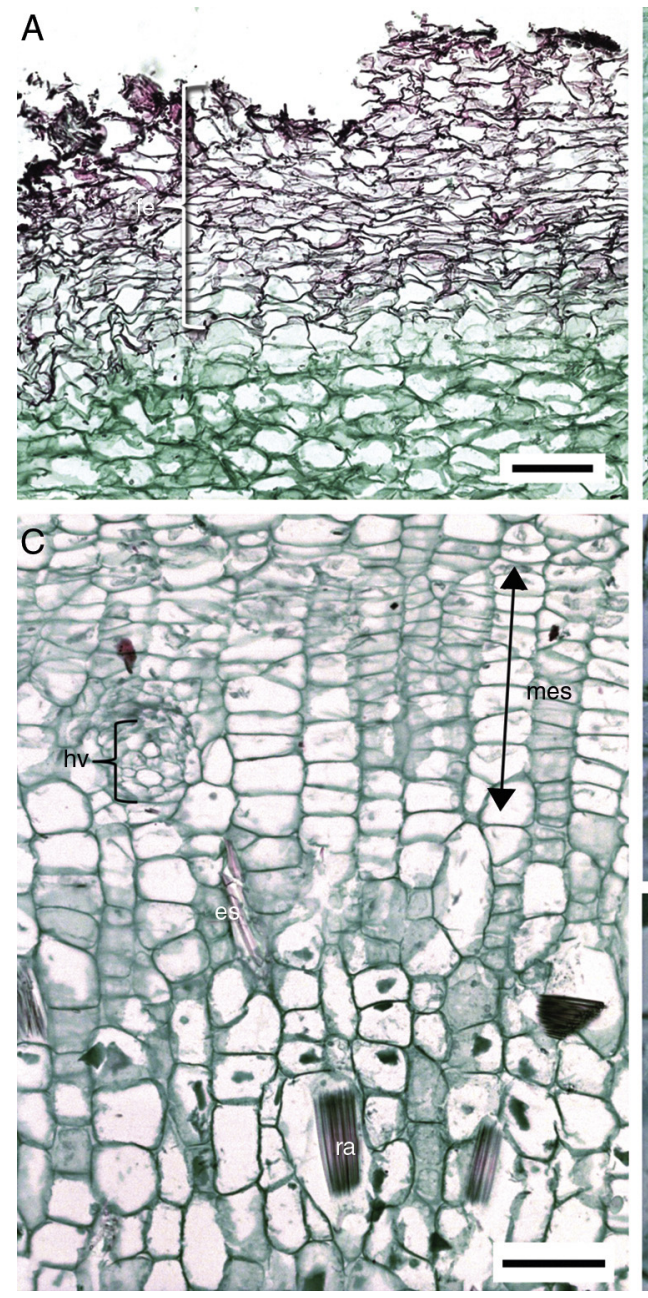
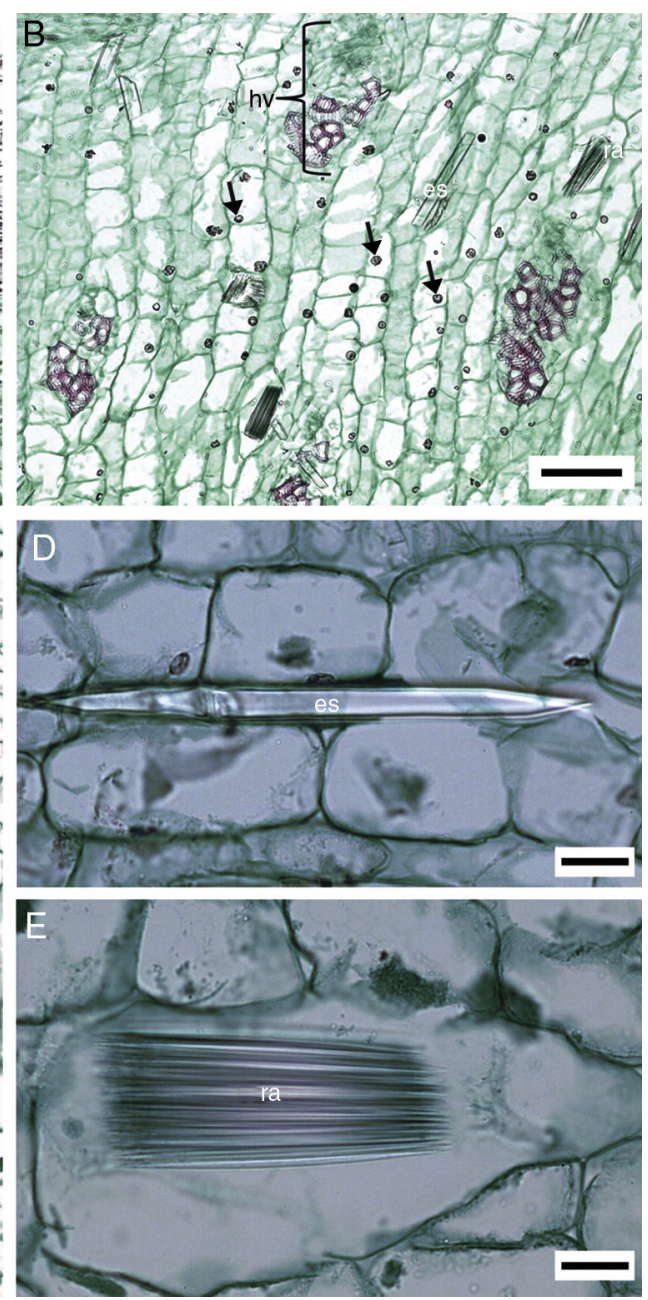

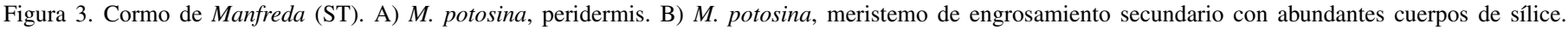

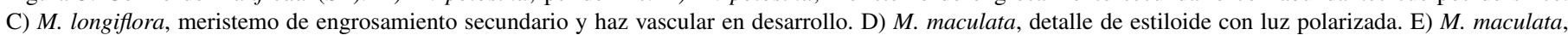
detalle de rafidio con luz polarizada. Barra es $100 \mu \mathrm{m}$ en A-C; $20 \mu \mathrm{m}$ en D y E.

Flecha: cuerpos de sílice. es: estiloide; fe: felema; hv: haz vascular; mes: meristemo de engrosamiento secundario; ra: rafidio.

cia entre las especies y muy poco entre individuos de la misma especie.

El parénquima abaxial de las bases de las láminas cercano a la epidermis tiene fibras discontinuas (fig. $4 \mathrm{E} \mathrm{y} \mathrm{F).} \mathrm{Con} \mathrm{respecto} \mathrm{a}$ la luz celular, las paredes son gruesas $(7.35 \mu \mathrm{m})$ en M. elongata, de grosor moderado $(4.9 \mu \mathrm{m})$ en Manfreda galvanie, $M$. guerrerensis, Manfreda guttata, M. hauniensis, Manfreda maculata, M. nanchititlensis y Manfreda pringlei; es variable en espesor (5-7 $\mu \mathrm{m})$ en $M$. pubescens y M. scabra. Las demás especies no tienen estas fibras. Los haces vasculares son colaterales y se localizan dispersos en el parénquima, los más externos son pequeños e indiferenciados, en ellos los elementos cribosos se diferencian antes que los elementos traqueales, y algunas veces se encuentran acompañados por fibras (fig. 4G y H) y asociadas a ellas estiloides. Los haces vasculares más internos son de mayor tamaño y completamente desarrollados, ovados o de forma irregular; las fibras acompañan al floema y al xilema en M. galvanie, M. guerrerensis, M. nanchititlensis, M. pringlei y $M$. pubescens; en $M$. nanchititlensis las fibras encierran completamente a los haces vasculares. En M. elongata, M. guttata,
M. maculata y M. scabra las fibras únicamente se asocian al floema, en M. hauniensis al xilema y en M. longiflora, M. potosina y $M$. singuliflora están ausentes, característica que permite la separación de las especies. En secciones longitudinales de la región basal del bulbo se observa el MEP. Este se distingue por la presencia de células dispuestas radialmente y en división en las bases de las hojas.

Anatomía de la hoja. En sección transversal, el perfil de la lámina de las hojas maduras tiene forma de « $\mathrm{V} »$ abierta o ligeramente ondulada (fig. 5A), únicamente es recta en M. potosina у $M$. singuliflora. Todas las especies tienen venación paralela, alternándose una vena de mayor grosor con otra más delgada, las venas de segundo orden son comunes y se extienden hacia la región intercostal (fig. 5B). La cutícula es lisa o estriada (fig. 5C y D); solo en M. longiflora, M. potosina, M. pringlei y $M$. pubescens se alternan porciones lisas y estriadas en una misma lámina, es generalmente delgada $(0.9-1.55 \mu \mathrm{m})$ y se observa gruesa $(2.85 \mu \mathrm{m})$ en $M$. nanchititlensis. La epidermis generalmente es papilosa en ambas superficies, con células prominentes. M. elongata solo tiene papilas en el envés, además es uniestrati- 

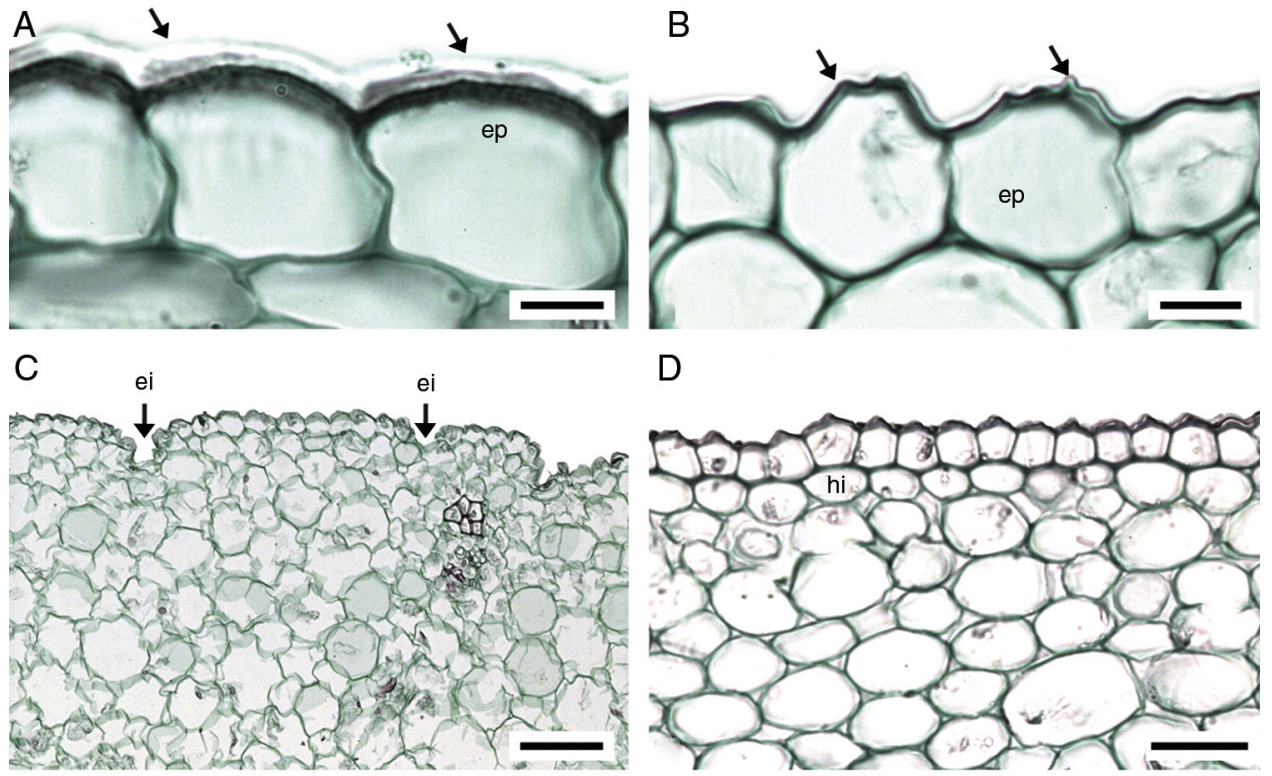

D
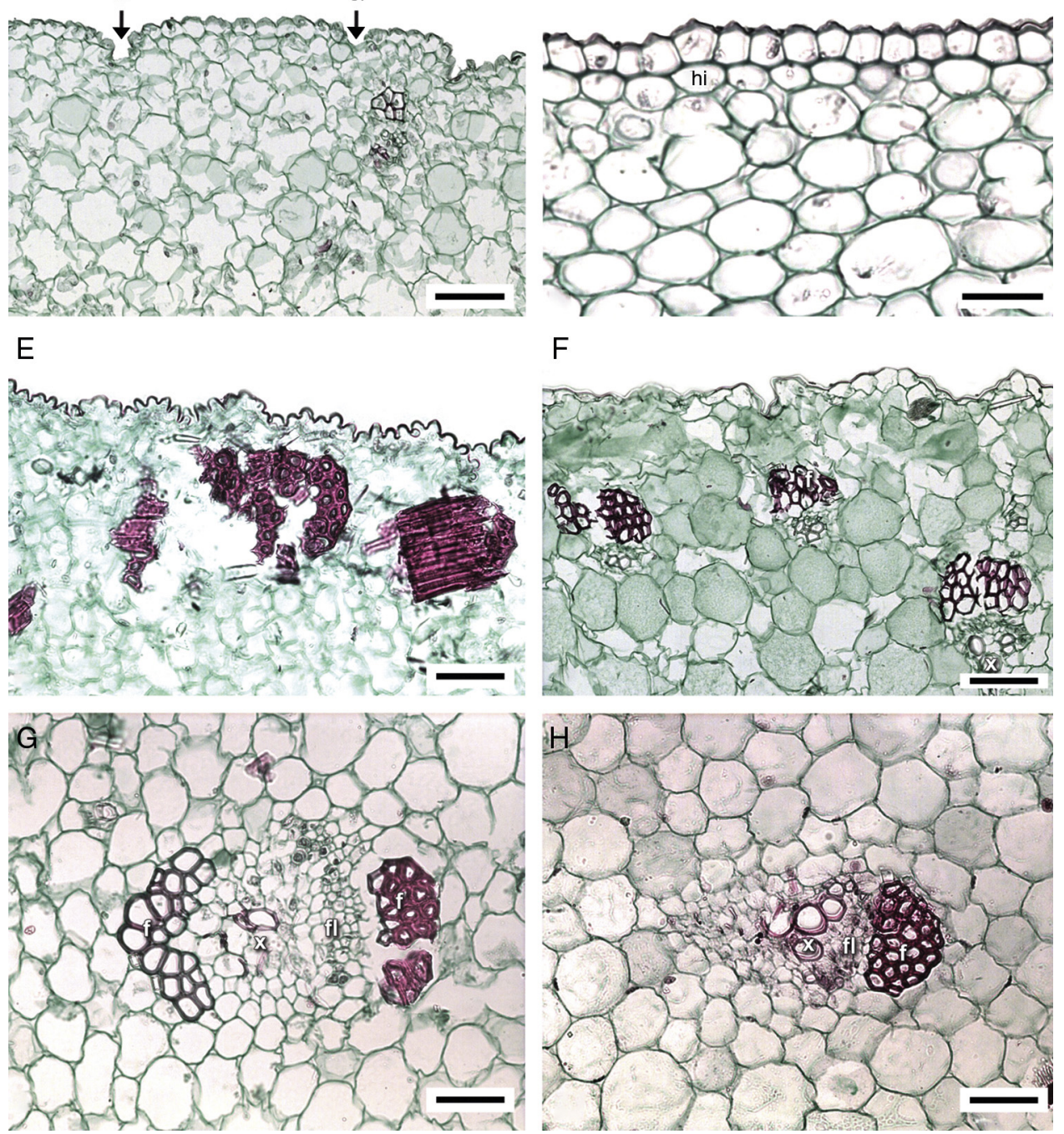

Figura 4. Bulbo y bases foliares de Manfreda (ST). A) M. nanchititlensis, cutícula lisa y muy gruesa. B) M. pubescens, cutícula estriada. C) M. potosina, epidermis con invaginaciones en el margen de las bases foliares. D) M. pubescens, hipodermis. E) M. elongata, banda discontinua de fibras. F) M. pringlei, bandas discontinuas de fibras. G) M. nanchititlensis, haz vascular con fibras asociadas al floema y xilema. H) M. maculata, haz vascular con fibras asociadas al floema. $10 \mu \mathrm{m}$ en A y B; $100 \mu \mathrm{m}$ en C y F; $50 \mu \mathrm{m}$ en D, E, G y H. Flecha: cutícula. ei: epidermis con invaginaciones; ep: epidermis; f: fibras; fl: floema; hi: hipodermis; x: xilema.

ficada, con células cuadradas a rectangulares. Las macropapilas en el envés son típicas de $M$. guttata y $M$. guerrerensis, mientras que en M. nanchititlensis y M. scabra se observan en ambas superficies. La lámina es anfiestomática, con estomas paracíti$\cos$ (fig. 5E); las células oclusivas presentan engrosamientos de cutina anteriores y posteriores (fig. 5F), excepto en M. longiflora y M. potosina. Los tricomas unicelulares abundantes, en ambas superficies, caracterizan a M. pubescens (fig. 5G); en esta especie se observa peridermis continua hacia el envés, el felógeno y la felodermis con 2 capas de células y el felema con 2 a
3 estratos (fig. 5H). Las hojas son unifaciales; el mesofilo está conformado únicamente por parénquima esponjoso y espacios intercelulares pequeños o medianos e idioblastos con rafidios y estiloides, que varían de escasos a abundantes (fig. 5I); son raros en M. maculata. Los rafidios se disponen en todo el mesofilo y son abundantes en las células subepidérmicas de $M$. longiflora, M. nanchititlensis y M. pringlei. Los estiloides se encuentran en el mesofilo, particularmente en las células próximas a los haces vasculares y están ausentes en M. guerrerensis y M. maculata. En sección transversal, los haces vasculares son colaterales y 

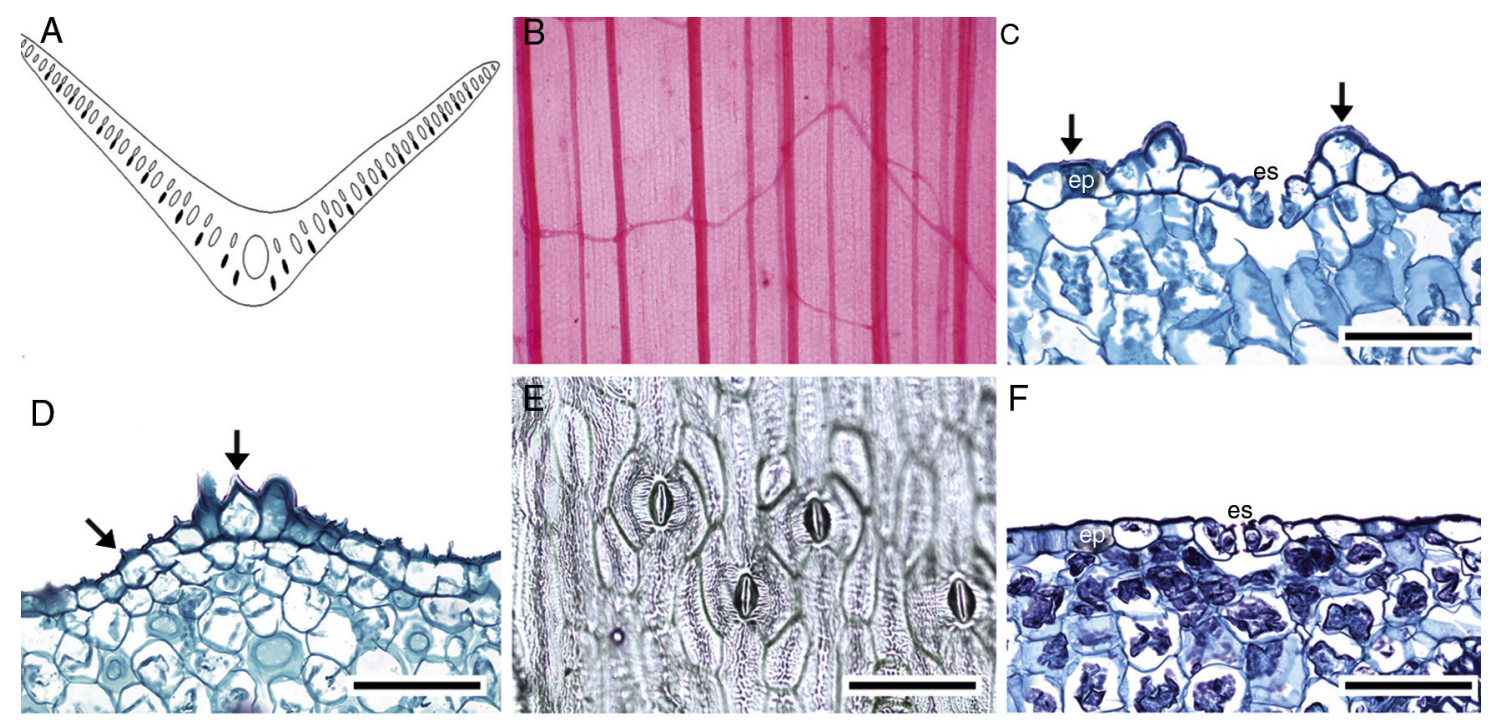

F
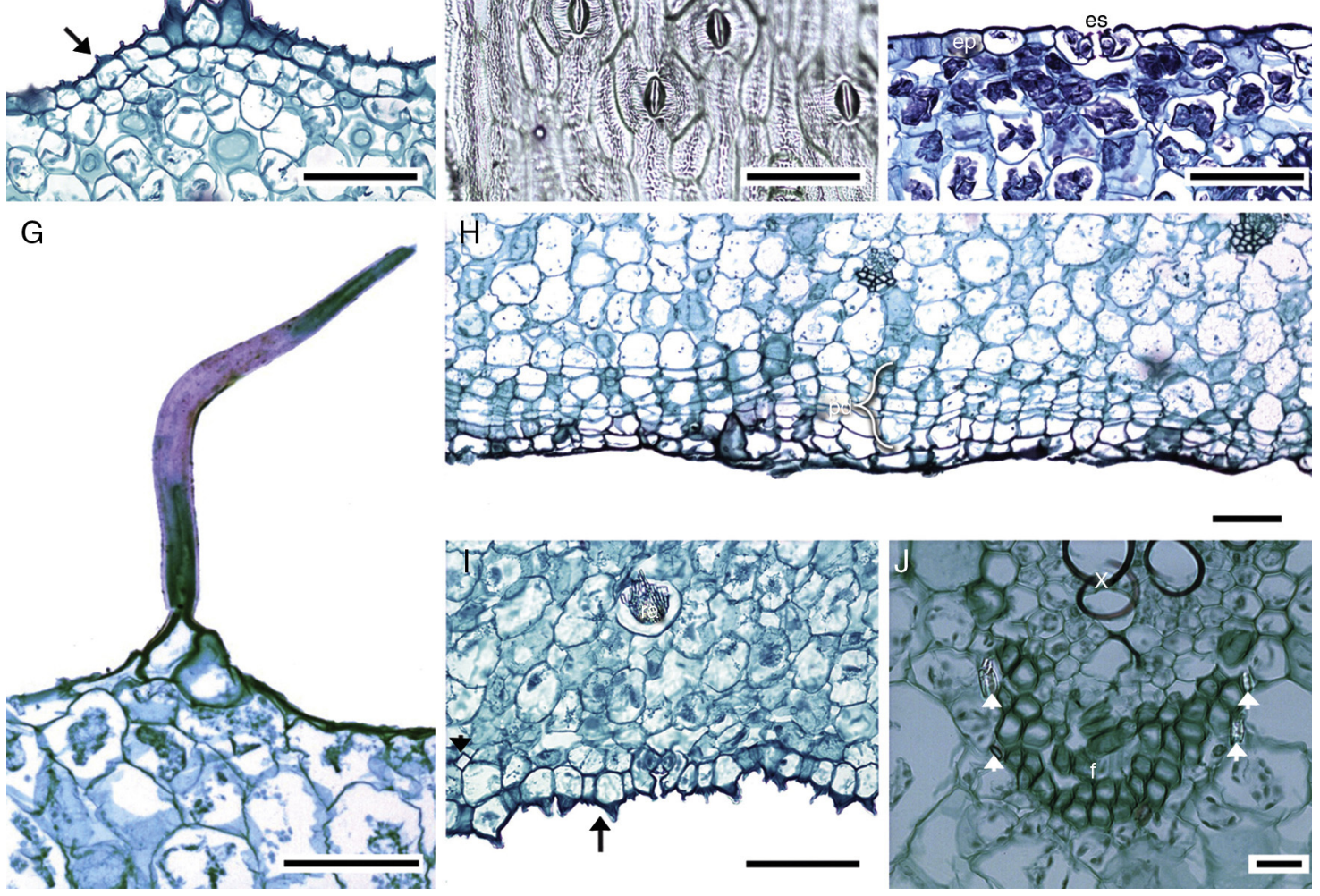

Figura 5. Hoja de Manfreda (ST). A) M. elongata, perfil de la lámina. B) M. elongata, patrón de venación. C) M. nanchititlensis, cutícula lisa. D) M. guttata, cutícula estriada. E) M. scabra, estomas paracíticos. F) M. revoluta, engrosamientos anteriores y posteriores de las células oclusivas. G) M. pubescens, tricoma. H) M. pubescens, peridermis. I) M. guttata, rafidios y estiloide. J) M. guttata, haz vascular con fibras, estiloides. Barra es $50 \mu \mathrm{m}$ en C-I; $20 \mu \mathrm{m}$ en J.

Flechas: cutícula; cabeza de flecha: estiloide. es: estoma; ep: célula epidérmica; f: fibras; pd: peridermis; ra: rafidio; x: xilema.

se disponen formando de una a 3 filas; en muchas especies se alterna un haz grande con otro pequeño. En las células cercanas al haz vascular hay fibras abundantes o escasas (fig. 5J), excepto en M. potosina y M. longiflora, donde están ausentes.

Anatomía de la base del pedúnculo floral. La cutícula es generalmente lisa, se observa estriada en $M$. pubescens y varía de gruesa a muy delgada (tabla 3). La epidermis es uniestratificada, con células cuadradas, generalmente papilosas (fig. 6A-C). Por debajo de la epidermis hay una zona de parénquima con células isodiamétricas, con rafidios y escasos estiloides asociados a las fibras (fig. 6D y E); estos están ausentes en $M$. longiflora y $M$. singuliflora, y los rafidios son escasos; en M. pringlei y M.pubescens pueden o no presentarse, cuando se presentan varían de escasos a abundantes. Esta zona de parénquima contiene haces vasculares colaterales discretos dispuestos en círculo. Por debajo de esta zona de parénquima, se observa un anillo de fibras, por su lignificación centrífuga y grosor de las paredes secundarias, maduran primero las fibras cercanas a la epidermis. Enseguida se observan otros haces vasculares colaterales, embebidos en células parenquimáticas, rafidios y fibras de escasas a abundantes (fig. $6 \mathrm{E}$ y F). Se observan fibras asociadas al floema de $M$. elongata, M. galvaniae, M. guttata, M. longiflora, M. maculata, $M$. potosina y $M$. singuliflora; asociadas al floema y al xilema en M. guerrerensis, M. nanchititlensis, M. pringlei y M. pubescens. En M. scabra este carácter es variable.

\section{Discusión}

No se registró ninguna característica anatómica propia de Manfreda, pero comparte con muchas Asparagales herbáceas la presencia de un MES, entre ellas: Agave, Aloe, Sansevieria (Cheadle, 1937; Chouard, 1936; Lu y Chiang, 1976); Patersonia (Rudall, 1984), Herreria montevidensis, Thysanotus spiniger (Rudall, 1995) y Polianthes (Solano et al., 2013), así como la 


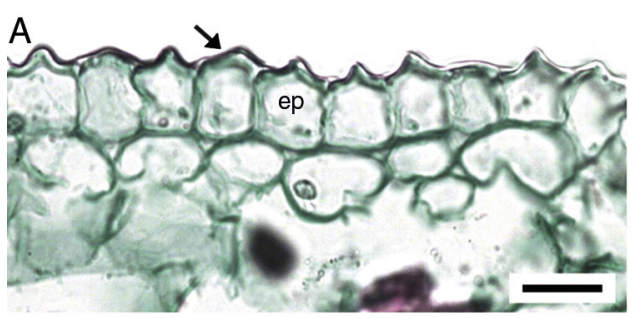

C

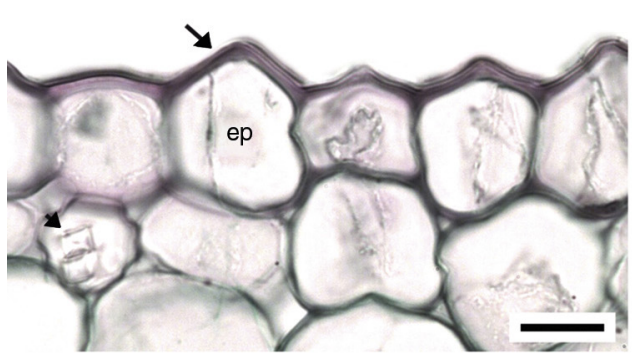

$E$

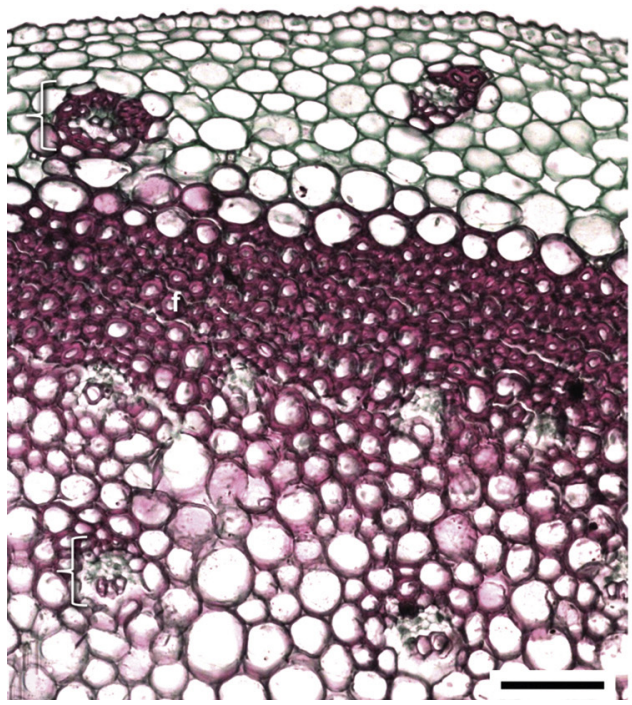

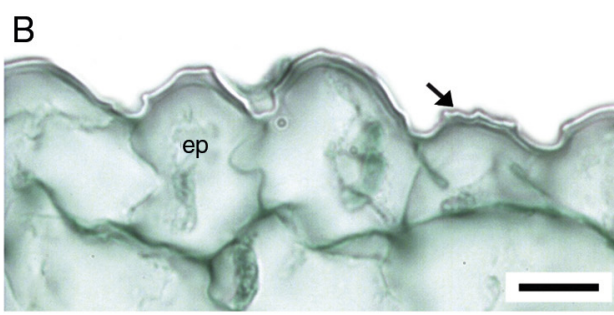

D
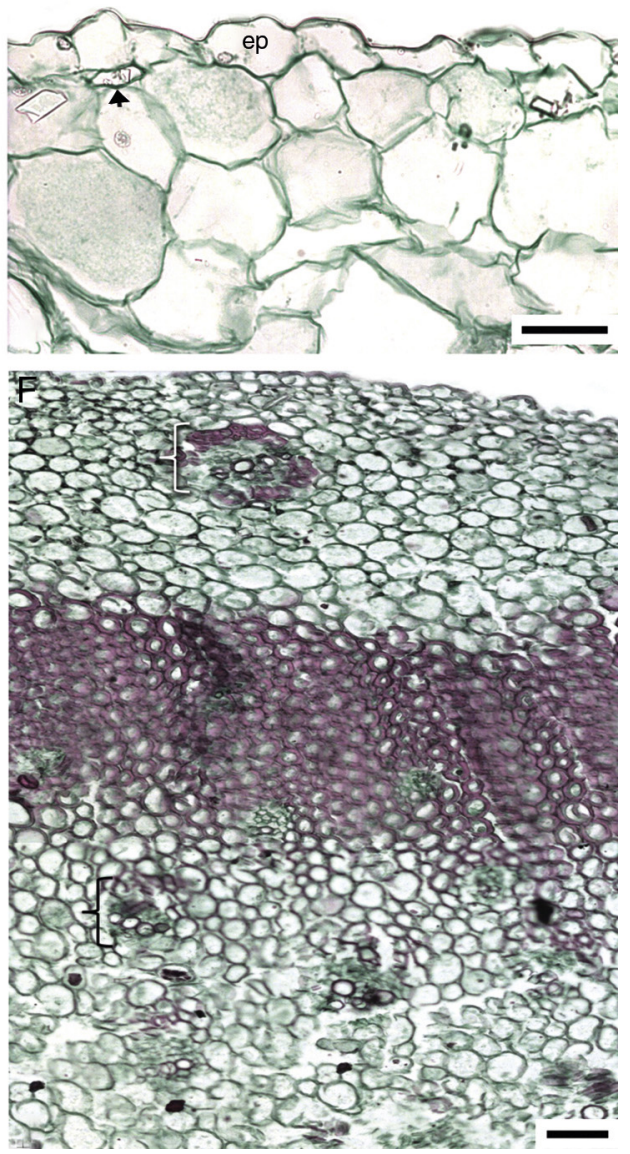

Figura 6. Anatomía de la base del pedúnculo del género Manfreda (CT). A) M. pubescens cutícula estriada, epidermis con papilas moderadamente desarrolladas: B) M. potosina, cutícula estriada, epidermis papilosa. C) $M$. scabra, cutícula lisa, epidermis papilosa. D) M. pringlei, estiloides debajo de la epidermis. E) $M$. pubescens, haces vasculares con fibras asociadas al floema y xilema y médula lignificada. F) M. galvanie, médula no lignificada. Barra es $20 \mu m$ en A y C; $10 \mu \mathrm{m}$ en B; $50 \mu \mathrm{m}$ en D; $100 \mu \mathrm{m}$ en E y F. Flecha: cutícula; cabeza de flecha: estiloide; llave: haz vascular. ep: epidermis; f: fibras.

presencia de rafidios presentes en varias familias de este orden como Agavaceae, Alliaceae, Amaryllidaceae, Asparagaceae, Convallariaceae $s$. $l$., Hypoxidaceae, Orchidaceae y Themidaceae (Arnott, 1981; Dahlgren et al., 1985; Gutiérrez et al., 2015; Prychid y Rudall, 1999; Rudall et al., 1998; Rudall, Engelman, Hanson y Chase, 1998; Solano et al., 2013; Stern, 1997). Las evidencias anatómicas con valor taxonómico que permiten delimitar especies o grupos de ellas en el género estudiado se sintetizaron en la tabla 3 y son una combinación de caracteres a veces para más de un órgano.

Morfología vegetativa. La presencia de cormo y bulbo en un mismo individuo se encuentra en todas las especies de Manfreda analizadas y no son frecuentes en las monocotiledóneas. Estos tallos han sido interpretados como formas transicionales entre bulbos, cormos o rizomas, presentes en Pseudotrimezia y
Trimezia (Iridaceae) (Chueirei-Chiaretto y de Menezes, 1980; Goldblatt, 1971; Rudall, 1989); también han sido observados en Polianthes (Asparagaceae, Agavoideae), aunque en este último caso ambos tallos están bien diferenciados (Solano et al., 2013). Las raíces contráctiles están ampliamente distribuidas en las monocotiledóneas y han sido descritas en Asparagales como Agave americana, Dasylirion acrotriche, Furcraea gigantea, Yucca aloifolia y Y. angustifolia (Rimbach, 1922), además de varias especies de Agave, Aloe brevifolia, Dasylirion wheeleri, Hesperoyucca whipplei, Nolina bigelovii, Manfreda maculosa (North, Briton y Garrett, 2008) y Polianthes (Solano et al., 2013). En Agave attenuata, Agave bovicornuta, Agave celsii, Yucca elephantipes y Yucca gloriosa están ausentes (North et al., 2008). Estas raíces se contraen por cambio de forma en las células del parénquima intermedias o internas, que se expanden radialmente 
Tabla 2

Inclusiones minerales en Manfreda (Asparagaceae, Agavoideae).

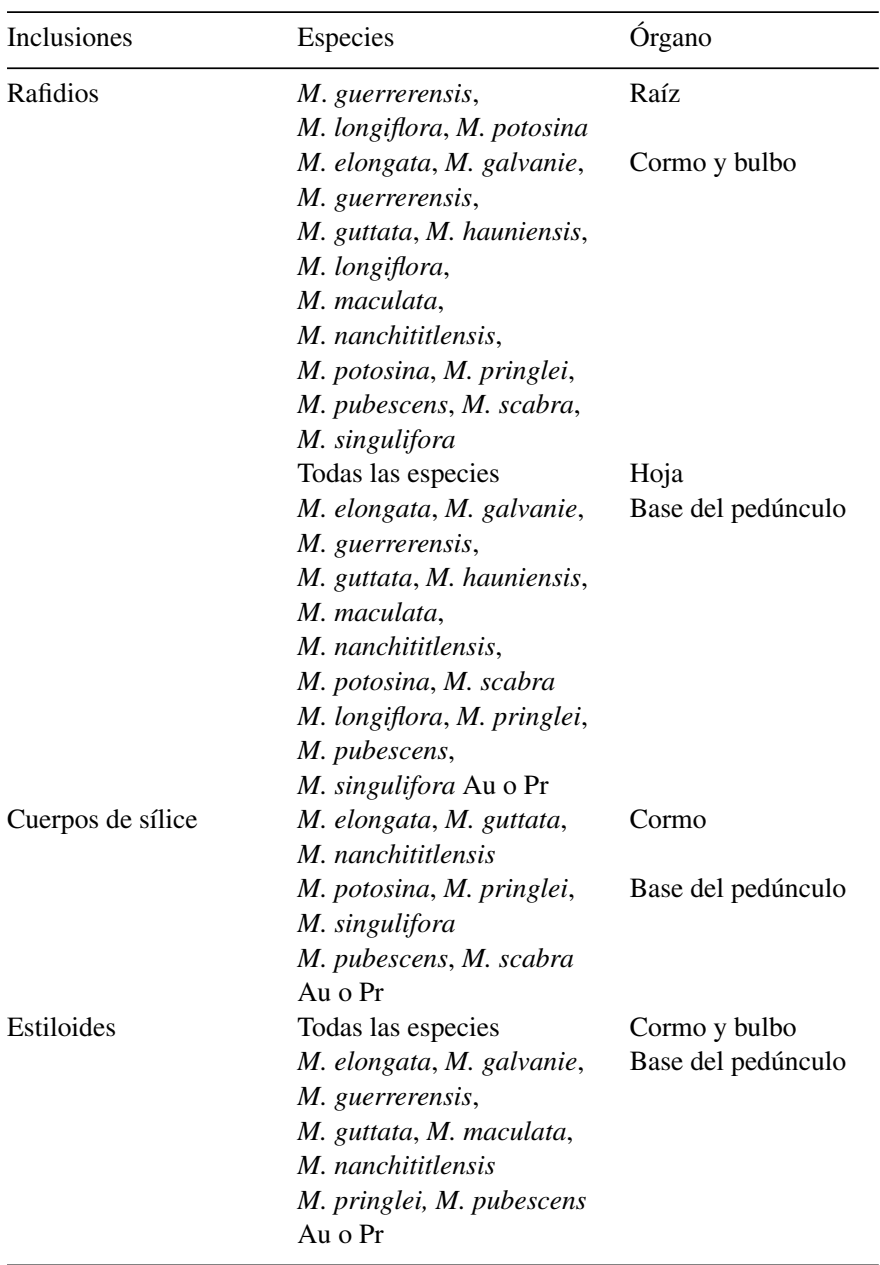

Au: ausente; Pr: presente a nivel individual.

y se acortan longitudinalmente (Jernstedt, 1984; Pütz, 2002), para enterrar el tallo y evitar daños por condiciones ambientales adversas (North et al., 2008).

Anatomía de la raíz. Las raíces de Manfreda tienen la estructura interna de muchas monocotiledóneas (Bowes, 2000). La exodermis pluriestratificada con rafidios también ha sido registrada en Asparagales como Agave, Furcraea y Yucca. En otras Asparagales, entre ellas, Agapanthus, Anthericum y Hosta, es uniestratificada, aunque Hosta carece de rafidios (Kauff et al., 2000). El anillo continuo o discontinuo de células con paredes engrosadas que rodean a la endodermis de $M$. guerrerensis, $M$. nanchititlensis, M. pubescens, $M$. scabra y M. singuliflora; según North et al. (2008), es típico en raíces contráctiles y permiten que las células del parénquima medias o internas donde ocurre la contracción no se rompan, permaneciendo estas células flexibles y con paredes delgadas, para aumentar la permeabilidad del agua en la zona de contracción (North y Peterson, 2005). La endodermis uniseriada también se presenta en otras Asparagales como H. whipplei (Asparagaceae) (North et al., 2008), Epidendrum saxatile, Lanium avicula, Polystachia estrellensis, Prescottia oligantha y Scaphyglottis modesta (Orchidaceae)
Tabla 3

Características anatómicas que ayudan a delimitar las 13 especies de Manfreda.

\begin{tabular}{ll}
\hline Especie & Órgano/carácter \\
\hline M. longiflora, M. potosina & $\begin{array}{l}\text { Raíz: células del parénquima } \\
\text { poliédricas }\end{array}$ \\
M. guerrerensis, & Rafidios cercanos a exodermis \\
$\begin{array}{l}\text { M. longiflora, } \text { M. potosina } \\
\text { M. scabra }\end{array}$ & $\begin{array}{l}\text { Anillo de 1-2 estratos de } \\
\text { esclerénquima colindante con la } \\
\text { endodermis }\end{array}$ \\
M. guerrerensis, & Anillo de 2 estratos \\
M. singuliflora & Anillo de 2-3 estratos \\
M. pubescens & Anillo de 4-5 estratos \\
M. nanchititlensis & Células endodérmicas con paredes \\
M. nanchititlensis & tangenciales engrosadas \\
M. longiflora, & Periciclo biseriado
\end{tabular}

M. nanchititlensis,

M. potosina,

M. pubescens, M. singuliflora

M. elongata, M. guttata,

M. nanchititlensis

M. potosina, M. pringlei,

M. singuliflora

M. pubescens, M. scabra

M. hauniensis.

M. elongata, M. hauniensis,

M. longiflora, M. potosina,

M. pubescens

M. galvanie, M. guerrerensis,

M. guttata, M. maculata,

M. nanchititlensis,

M. pringlei, M. scabra,

M. singuliflora

Demás especies

M. potosina

M. elongata,

M. nanchititlensis,

M. pubescens

M. pubescens

M. elongata, M. galvani,

M. guerrerensis, M. guttata,

M. haunienis, M. maculata,

M. nanchititlensis,

M. pringlei, M. pubescens,

M. scabra

M. galvanie, M. guerrerensis,

M. nanchititlensis,

M. pringlei, M. pubescens

M. nanchititlensis

M. elongata, M. guttata,

M. maculata, M. scabra

M. potosina, M. singuliflora

Demás especies

M. nanchititlensis

M. elongata

M. guerrerensis, $M$. guttata

M. longiflora, M. potosina

M. pubescens
Cormo: cuerpos de sílice próximos al MES presentes

Cuerpos de sílice próximos al MES presentes o ausentes

Cuerpos de sílice ausentes

Bulbo: cutícula delgada

(0.94-1.64 $\mu \mathrm{m})$

Cutícula gruesa (2.36-3.76 $\mu \mathrm{m})$

Cutícula moderadamente gruesa (1.65-2.35 $\mu \mathrm{m})$

Bases foliares de la epidermis con invaginaciones

Estrato de células por debajo de la epidermis similares a esta

Rafidios en las células subepidérmicas

Banda de fibras variable en continuidad y grosor, en el parénquima cercano a la epidermis

Banda de fibras próximas al xilema y floema

Banda de fibras rodeando los haces vasculares

Fibras asociadas al floema

Hoja: lámina recta

Lámina en forma de «V» abierta

o ligeramente ondulada

Cutícula gruesa $(>2.20 \mu \mathrm{m})$

Papilas en el envés

Macropapilas en la cara abaxial

Células oclusivas con prolongaciones o engrosamiento de cutina ausentes

Tricomas en ambas superficies 
Tabla 3

(continuación)

\begin{tabular}{|c|c|}
\hline Especie & Órgano/carácter \\
\hline M. pubescens & $\begin{array}{l}\text { Peridermis continua en la cara } \\
\text { abaxial }\end{array}$ \\
\hline M. maculata & $\begin{array}{l}\text { Peridermis discontinua en la cara } \\
\text { abaxial }\end{array}$ \\
\hline M. guerrerensis, M. maculata & Mesofilo con estiloides ausentes \\
\hline M. potosina, M. longiflora & Fibras ausentes \\
\hline M. elongata, $M$. guttata & Pedúnculo: cutícula delgada \\
\hline M. potosina, $M$. singuliflora & $(<1 \mu \mathrm{m})$ \\
\hline $\begin{array}{l}\text { M. guerrerensis, } \\
\text { M. longiflora, } \\
\text { M. maculata, M. pringlei, } \\
\text { M. pubescens, M. scabra }\end{array}$ & $\begin{array}{l}\text { Cutícula moderadamente gruesa } \\
(1.5-2.0 \mu \mathrm{m})\end{array}$ \\
\hline $\begin{array}{l}\text { M. galvanie, M. hauniensis, } \\
\text { M. nanchititlensis }\end{array}$ & Cutícula gruesa $(>2.5 \mu \mathrm{m})$ \\
\hline $\begin{array}{l}\text { M. hauniensis, M. longiflora, } \\
\text { M. singuliflora }\end{array}$ & $\begin{array}{l}\text { Parénquima próximo a la epidermis } \\
\text { sin estiloides }\end{array}$ \\
\hline
\end{tabular}

En negritas se indica el órgano de observación.

(Franco e Isaías, 2008) e Iris germanica (Iridaceae) (Meyer, Seago y Peterson, 2009).

En Asparagales el periciclo puede ser uni, bi o multiseriado, en Manfreda es del primer tipo y también se presenta en Agapanthus, Allium, Dracaena, Eriospermum, Sansevieria y Tulbaghia, entre otros géneros, mientras que en Aphyllanthes, Beaucarnea, Dasylirion, Nolina y Yucca es pluriestratificado (Kauff et al., 2000). Las raíces de las manfredas presentan una región central de parénquima, que autores como Kauff et al. (2000) describieron para Agave, Beaucarnea, Dracaena, Furcraea, Nolina y Yucca, y la llaman médula; sin embargo, este término no debería emplearse porque no es homólogo a la médula de los tallos.

Anatomía del cormo. En el cormo de Manfreda se observa un MES. Su presencia confirma la hipótesis de Rudall (1995), quien sugirió que este tejido es común en Agavaceae, el cual ha sido descrito en Agave y Furcraea, además de Polianthes (Solano et al., 2013). Tomlinson y Zimmermann (1969) también observaron este meristemo en otros géneros de Agavaceae, entre ellos Yucca. Cattai y de Menezes (2010) demostraron que el MES en Cordyline fructicosa se origina a partir del periciclo. Según Rudall (1984), este tejido se desarrolla en tallos hipógeos de Patersonia, un género endémico de Australia y Asia. Pocas especies de monocotiledóneas no arborescentes tienen MEP y MES, como Eucomis (Reyneken y van der Schijff, 1972), Allium (de Mason, 1979), varias especies con tallos rizomatosos de Liliaceae $s$. $l$. (Coetzee y van der Schijff, 1969), algunos miembros de Iridaceae (Rudall, 1984), Polianthes (Solano et al., 2013) y ahora Manfreda, todas ellas clasificadas como hierbas perennes, porque la parte aérea desaparece durante la época desfavorable del año.

El tejido fundamental del tallo de las monocotiledóneas comúnmente contiene oxalato de calcio en forma de rafidios (de Cordemoy, 1893). Chin-Yi y Chiang (1976) indicaron la presencia de rafidios y estiloides en el MEP, en el MES y en el parénquima cortical de Agave rigida y Aloe vera. En Polianthes se observa un patrón similar (Solano et al., 2013) y ahora en las especies de Manfreda aquí estudiadas, con rafidios y estiloides en los tejidos primarios y secundarios. En la mayoría de las especies de Manfreda los rafidios son abundantes, únicamente en $M$. pringlei y $M$. singuliflora son escasos. Una variación semejante fue observada en otros géneros de monocotiledóneas (Brittan, 1970). Estas variaciones en el contenido de Ca del tallo ocurren usualmente en las angiospermas en el nivel de orden y en categorías taxonómicas superiores, en general, el contenido de Ca del tallo es mayor en los órdenes de eudicotiledóneas, comparado con las monocotiledóneas (Broadley et al., 2003). En este grupo de plantas muchos órdenes de Commelinoides, entre ellas, Arecales, Commelinales, Poales y Zingiberales, tienen menor contenido de Ca que otros órdenes, por ejemplo, en Asparagales (Broadley et al., 2003), como registraron en Polianthes Solano et al. (2013).

La presencia de cuerpos de sílice en Asparagales fue observado por primera vez en el parénquima de la región central del cormo en Polianthes (Solano et al., 2013) y ahora en las especies de Manfreda analizadas en este trabajo, excepto en M. hauniensis. Este resultado incrementa el número de órdenes registrados por Prychid, Rudall y Gregory (2004) con este contenido mineral. Los cuerpos de sílice usualmente se encuentran en la epidermis (e.g., en gramíneas, comelinas y juncos), esclerénquima subepidérmico y en la vaina de los haces vasculares (e.g., palmas, bananas y orquídeas (Prychid et al., 2004), pero raros en el parénquima de los tallos. Según Solano et al. (2013), los cuerpos de sílice en Polianthes contienen el 21-25\% de Si, el 24-40\% de O, el 3-6\% de Al y el 2-3\% de K; es probable que una composición similar se presente en los cuerpos de sílice de las especies de Manfreda, porque tienen una fuerte similitud a los observados con microscopia de luz en Polianthes (Solano et al., 2013). Los cuerpos de sílice tienen valor diagnóstico en la delimitación de las subfamilias y géneros de Asparagales; este valor también fue indicado para otras monocotiledóneas por Dahlgren (1980) y Prychid et al. (2004).

Haces vasculares colaterales han sido observados en varias especies de mocotiledóneas (Ye, 2002), como Trimezia martinicensis y Neomarica nortiana, además de Polianthes (Solano et al., 2013). Haces vasculares anfivasales también han sido descritos en mocotiledóneas como Yucca whipplei y varias especies de Iris y Patersonia (Tomlinson y Zimmermann, 1969; Rudall, 1984). En este grupo de plantas con atactostele típica, durante el crecimiento primario es difícil diferenciar el córtex y el cilindro vascular, como ocurre en Beaucarnea (Stevenson, 1980), Polianthes (Solano et al., 2013) y en las especies de Manfreda aquí analizadas. Sin embargo, cuando el MES ha iniciado su actividad y el crecimiento secundario se ha establecido como en Polianthes (Solano et al., 2013) y Manfreda, es posible diferenciar ambas regiones. Los haces vasculares primarios y secundarios son continuos; estos últimos producen centrípetamente el MES, que se dispone en líneas radiales separadas por células parenquimáticas; este mismo patrón fue descrito en Polianthes por Solano et al. (2013) y ahora en Manfreda. ChinYi y Chiang (1976) y Diggle y de Mason (1983) observaron que, en sección transversal, los haces vasculares primarios de Aloe son pequeños, con poco xilema y floema, comparados con los haces secundarios. 
Con respecto a la peridermis, en Aloe y Agave el felógeno tiene crecimiento bidireccional y se origina del parénquima subepidérmico por divisiones celulares periclinales (Chin-Yi y Chiang, 1976). En Polianthes el felógeno es unidireccional, probablemente, este crecimiento se relaciona con el tamaño pequeño del cormo de estas plantas, en comparación con otras especies de monocotiledóneas (Solano et al., 2013). En Manfreda el felógeno también tiene desarrollo unidireccional, el cual se asocia a la talla pequeña de las plantas de este género.

Anatomía de la hoja. En las monocotiledóneas el perfil de la lámina abierta de las hojas maduras en sección transversal es un carácter diagnóstico en el nivel de especie (Rudall y Mathew, 1993). Sin embargo, en Polianthes se describieron 2 tipos de perfil recto y en forma de «U». Ambos tipos de perfil se presentan en individuos de la misma especie, por lo tanto, el carácter no es diagnóstico en este nivel taxonómico, es probable que el perfil de la lámina este en función del grado de desarrollo de la misma (Solano et al., 2013). En Manfreda la mayoría de las especies tienen perfil de la lámina madura en forma de $« \mathrm{~V} »$ abierta o ligeramente ondulada, únicamente es recta en $M$. potosina, M. pubescens y $M$. singuliflora. En otras Asparagales, como Iris juncea, la lámina es oval, en Iris subgénero Hermadactyloides cuadrada o en forma de «V» para Iris xanthoclora (Rudall y Mathew, 1993) y varias especies de Milla (Gutiérrez et al., 2015).

La cutícula gruesa $(2.21-2.85 \mu \mathrm{m})$ separa a $M$. nanchititlensis. La cutícula gruesa es característica de otros géneros de Agavaceae con hojas persistentes, adaptados a climas secos, como Agave, Beschorneria, Furcraea y Yucca (Álvarez, 1990; Blunden y Binns, 1970), aunque Manfreda tiene hojas caducas. Solo $M$. elongata tiene papilas en el envés y las macropapilas en esta región caracterizan a $M$. guttata. Las papilas también han sido registradas sobre las venas de Beschorneria, Prochnyanthes, Hesperaloe, Yucca (Verhoek-Williams, 1998) y Polianthes (Solano et al., 2013).

Los tricomas son poco comunes en la familia Agavaceae; cuando se presentan estos son simples (Verhoek-Williams, 1998). Por ejemplo, se han observado en la lámina de Polianthes graminifolia (Solano et al., 2013) y aquí se encontraron en M. pubescens. La lámina es anfiestomática. El complejo estomático es variable en Agavaceae. En la mayoría de las especies de Manfreda analizadas en este estudio los estomas son paracíticos. Álvarez (1990) y Solano et al. (2013) también los observaron en Polianthes. Aunque Shah y Gopal (1970) indican que en $P$. tuberosa son anomocíticos; tetracíticos en Agave, Beschorneria, Clistoyucca, Furcraea, Hesperaloe, Hesperoyucca, Samuela y varias especies de Yucca (Álvarez, 1990; Blunden y Jewers, 1973; Gentry y Sauck, 1978); en otras especies de este último género son anomocíticos (Blunden y Binns, 1970). En Manfreda variegata se distingue un reborde que rodea a las células oclusivas; este también fue descrito por Álvarez (1990) en Manfreda brachystachya (= M. scabra) como una ligera proyección o labio, aunque en este trabajo el reborde se observó paralelo a las células oclusivas de esta especie. Este reborde se considera una adaptación de muchas agaváceas a condiciones de sequía severa y su función se rela- ciona con la pérdida de agua (McCledon, 1908; Roux-López, 1964).

Blunden y Jewers (1973) refieren que en Agavaceae el parénquima en empalizada puede o no estar presente, como se ha confirmado para Beschorneria, Polianthes (García-Mendoza, 1987; Solano et al., 2013) y ahora Manfreda con solo parénquima esponjoso. Goldblatt (1990) menciona que al menos en Iridaceae el mesofilo indiferenciado es plesiomórfico. Los rafidios son las inclusiones minerales más comunes en las monocotiledóneas (Grayum, 1990; Nicholson, 1960; Prychid y Rudall, 1999); esta generalización fue corroborada en Polianthes por Solano et al. (2013), donde solo en Polianthes densiflora están ausentes. En Manfreda estos idioblastos también están presentes en todos los órganos estudiados, excepto en la raíz de M. hauniensis.

Anatomía de la base del eje de la inflorescencia. La cutícula de este órgano por lo general es lisa; se observa estriada únicamente en $M$. pubescens. En Polianthes la cutícula de la base del eje de la inflorescencia es generalmente lisa (Solano et al., 2013). En la mayoría de las especies de Manfreda analizadas en este trabajo, la cutícula es gruesa a moderadamente gruesa. En todas las especies de Manfreda se observa una banda de esclerénquima que funciona como soporte del eje floral. Una banda similar ha sido observada en Thysanotus (Asparagaceae), varias especies de Iridaceae y Xyridaceae (Brittan, 1970; Rudall, 1984; Scatena, Caetano y Oriani, 2011), además en 13 especies de Polianthes (Solano et al., 2013). Es pertinente señalar que es necesario evaluar este carácter en otros géneros de Asparagaceae, para entender su significado evolutivo. Según Brittan (1970), las fibras asociadas a los haces vasculares pueden o no estar presentes en las especies de un mismo género. Esta situación también fue observada en Polianthes (Solano et al., 2013) y ahora en Manfreda.

Las especies de Manfedra estudiadas desarrollan 2 tipos de tallo hipógeo: un cormo y un bulbo. A diferencia de otras monocotiledóneas, en todas las especies de Manfreda analizadas se desarrolla un MES y en el cormo no se observa esclerénquima, pero casi todas las especies presentan cuerpos de sílice. Hay caracteres anatómicos únicos o combinación de ellos que permiten separar especies o grupos de especies de este género, y estos podrían utilizarse en análisis filogenéticos.

\section{Agradecimientos}

Esta investigación fue apoyada por el Programa de Apoyo a Proyectos de Investigación e Innovación Tecnológica, UNAM, convenio IN211103, cuyo responsable fue el primer autor. También se agradece a Ana Ruth de la Cruz M. y a Ramiro Ríos Gómez por su apoyo en el trabajo de campo y laboratorio; así como a Julio César Montero Rojas por el diseño de las figuras. Agradecemos los comentarios de 2 revisores anónimos.

\section{Referencias}

Álvarez, A. (1985). El complejo estomático en la familia Agavaceae I. Desarro1lo. Feddes Repertorium, 96, 693-704

Álvarez, A. (1990). El complejo estomático en la familia Agavaceae II. Epidermis adulta. Feddes Repertorium, 101, 113-114. 
APG III (Angiosperm Phylogeny Group) (2009). An update of the Angiosperm Phylogeny Group classification for the orders and families of flowering plants. Botanical Journal of the Linnean Society, 161, 105-121.

Arnott, H. J. (1981). An SEM study of twinning in calcium oxalate crystals of plants. Scanning Electron Microscopy, 3, 225-234

Blunden, G. y Binns, W. W. (1970). The leaf anatomy of Yucca glauca Nutt. Botanical Journal of the Linnean Society, 63, 133-141.

Blunden, G. y Jewers, K. (1973). The comparative leaf anatomy of Agave, Beschorneria, Doryanthes and Furcraea species (Agavaceae: Agaveae). Botanical Journal of the Linnean Socciety, 66, 157-179.

Bowes, B. G. (2000). A color atlas of plant structure. Ames, Iowa: State University Press.

Brittan, N. H. (1970). A preliminary survey of the stem and leaf anatomy of Thysantus R Br. Liliaceae. Botanical Journal of the Linnean Society, 63, $57-70$.

Broadley, M. R., Bowen, H. C., Cotterill, H. L., Hammond, J. P., Meacham, M. C., Mead, A., et al. (2003). Variation in the shoot calcium content of angiosperms. Journal of Experimental Botany, 54, 1431-1446.

Carlquist, S. (1982). The use of ethilendiamine in softening hard plant structures for paraffin sectioning. Stain Technology, 57, 31-37.

Castillejos, C. C. (2009). Sistemática del género Manfreda (Agavaceae) (tesis doctoral). Montecillo, Estado de México: Colegio de Postgraduados.

Cattai, M. B. y De Menezes, N. L. (2010). Primary and secondary thickening in the stem of Cordyline fruticosa (Agavaceae). Anais da Academia Brasileira de Ciências, 82, 653-662.

Cetzal-Ix, W., Noguera-Savelli, E., Jáuregui, D. y Carnevali, G. (2013). Anatomía foliar comparada y sistemática del clado-Trichocentrum con énfasis en Cohniella (Asparagales: Orchidaceae). Revista de Biología Tropical, 61, $1841-1858$

Chakraverti, D. N. (1939). Secondary growth in the bulb of Polianthes tuberosa L. Current Science, 8, 263-264.

Cheadle, V. I. (1937). Secondary growth by means of a thickening ring in certain monocotyledons. Botanical Gazette, 98, 535-555.

Chin-Yi, L. y Chiang, S. H. (1976). Lateral thickening in the steam of Agave rigida and Aloe vera. Taiwania, 21, 204-219.

Chouard, P. (1936). La nature et le role des formations dites "secondaires" dans l'edification de la tige des Monocotyledones. Bulletin de la Société Botanique de France Paris, 83, 819-836.

Chueirei-Chiaretto, I. A. y de Menezes, N. L. (1980). Considerations on morphological and phylogenetic characteristics of the corm of Trimezea (Iridaceae). Boletim de Botanica, Departamento de Botanica, Instituto de Biociencias, Universidade de Sao Paulo, 8, 1-6.

Claus, E. P. (1954). A study of the root system of Hemerocallis fulva L. I. Morphology and histology. Journal of the American Pharmaceutical Association, 43, 188-191.

Conran, J. G. (1999). Anatomy and morphology of Behnia (Behniaceae) and its relationships within Lilianae: Asparagales. Botanical Journal of the Linnean Society, 131, 115-129.

Coetzee, J. y van der Schijff, H. P. (1969). Secondary thickening in geophytyc Liliaceae. Journal of South African Botany, 35, 99-108.

Dahlgren, R. M. T. (1980). A revised system of classification of the angiosperm. Botanical Journal of the Linnean Society, 80, 91-124.

Dahlgren, R. M. T., Clifford, H. T. y Yeo, P. F. (1985). The families of the monocotyledons: structure, evolution and taxonomy. New York: Springer.

De Cordemoy, H. J. (1893). Sür le role des tissues secondaries a reserves des monocotyledons arborescents. Comptes Rendus de l'Académie des Sciences, 117, 132-134.

De Mason, D. A. (1979). Function and development of the primary thickening meristem in the monocotyledon Allium cepa L. Botanical Gazzete, 140, $51-56$.

Diggle, P. K. y de Mason, D. A. (1983). The relationship between the primary thickening meristem and the secondary thickening meristem in Yucca whipplei Torr I. Histology of the mature vegetative stem. American Journal of Botany, 70, 1195-1204.

Franco, A. S. P. y Isaías, R. M. S. (2008). Comparative anatomy of the absorption roots of terrestrial and epiphytic orchids. Brazilian Archives of Biology and Technology, 51, 83-93.
Fritsch, R. (1992). Zur Wurzelanatomie in der Gattung Allium L. (Alliaceae). Beitrage zur Biologie der Pflanzen, 67, 129-160.

García-Mendoza, A. (1987). Monografia del género Beschorneria Kunth (Agavaceae) (Tesis de maestría). Universidad Nacional Autónoma de México Mexico D.F.

García-Mendoza, A. (1995). Riqueza y endemismos de la familia Agavaceae en México. En E. Linares, P. Dávila, F. Chiang, R. Bye, y T. Elías (Eds.), Conservación de plantas en peligro de extinción: diferentes enfoques (51-75). México, D.F.: Instituto de Biología, Jardín Botánico, Universidad Nacional Autónoma de México.

Gentry, H. S. y Sauck, J. R. (1978). The stomatal complex in Agave: groups Deserticolae, Campaniflorae Umbelliflorae. Proceedings of the California. Academy of Sciences, 41, 371-387.

Goldblatt, P. (1971). Cytological and morphological studies in the southern African Iridaceae. Journal of South African Botany, 37, 317-460.

Goldblatt, P. (1990). Phylogeny and classification of Iridaceae. Annals of the Missouri Botanical Garden, 77, 607-627.

Grayum, M. H. (1990). Evolution and phylogeny of the Araceae. Annals of Missouri Botanical Garden, 77, 628-697.

Gutiérrez, J., Salgado, J., Grego-Valencia, D. y Terrazas, T. (2015). Morfología y anatomía foliar de los géneros del complejo Milla (Themidaceae). Revista Mexicana de Biodiversidad, 88, 652-660.

Hickey, L. J. (1973). Classification of the architecture of dicotyledons leaves. American Journal of Botany, 60, 17-33.

Jernstedt, J. A. (1984). Root contraction in hyacinth I Effects of IAA on differential cell expansion. American Journal of Botany, 71, 1080-1089.

Johansen, D. A. (1940). Plant microtechnique. New York: MCGraw Hill.

Kauff, F., Rudall, P. J. y Conran, J. G. (2000). Systematic root anatomy of Asparagales and other monocotyledons. Plant Systematics and Evolution, 223, 139-154.

Lu, C. Y. y Chiang, S. T. (1976). Lateral thickening in the stem of Agave rigida Mill. and Aloe vera L. Taiwania, 21, 204-219.

Mangin, L. (1882). Origine et insertion des racines adventives et modifications correlatives de la tige chez les monocotyledones. Annales des Sciences Naturelles; Botanique, Série 6, 14, 216-363.

McCledon, J. F. (1908). On xerophytic adaptations of leaf structure in Yucca, Agave and Nolina. American Naturalist, 42, 306-308.

Meyer, C. J., Seago, J. L., Jr. y Peterson, C. A. (2009). Environmental effects on the maturation of the endodermis and multiseriate exodermis of Iris germanica roots. Annals of Botany, 103, 687-702.

Nicholson, D. H. (1960). The occurrence of trichoscleroids in the Monsteroideae (Aracaeae). American Journal of Botany, 47, 598-602.

Nobel, P. S. (1998). Los incomparables agaves y cactos. México D.F.: Trillas.

North, G. B. y Peterson, C. A. (2005). Water flow in roots: structural and regulatory features. En N. M. Holbrook y M. A. Zwieniecki (Eds.), Vascular transport in plants (pp. 131-156). San Diego, CA: Elsevier Academic Press.

North, G. B., Briton, E. K. y Garrett, T. Y. (2008). Contractile roots in succulent monocots: convergence, divergence and adaptation to limited rainfall. Plant, Cell and Environment, 31, 1179-1189.

Pant, D. D. (1943). On the morphology and anatomy of the root system in Asphodelus tenuifolius Cavan. Journal of the Indian Botanical Society, 22, $1-26$.

Piña, L. I. (1985). Consideraciones sobre el género Manfreda I. Cactáceas y suculentas mexicanas, 74, 27-32.

Prychid, C. J. y Rudall, P. J. (1999). Calcium oxalate crystals in monocotyledons: a review of their structure and systematics. Annals of Botany, 84, $725-739$

Prychid, C. J., Rudall, P. J. y Gregory, M. (2004). Systematics and biology of silica bodies in monocotyledons. Botanical Review, 69, 377-440.

Pütz, N. (2002). Contractile roots. En Y. Waisel, A. Eshel, y U. Kafkafi (Eds.), Plant roots. (pp. 975-987). New York: Marcel Dekker.

Reyneken, W. F. y van der Schijff, H. P. (1972). Primary thickening in the stem of the Eucomis pallidiflora Beker. Berichte Deustchen Botanischen Gesellschaft, 85, 10-12.

Rimbach, A. (1922). Die Wurzelverkürzung bei den großen Monokotylenformen. Berichte der Deutschen Botanischen Gesellschaft, 40, 196-202. 
Rose, J. N. (1899). Studies of Mexican and Central American plants No 2. A proposed rearrangement of the suborder Agaveae. Contributions from the National Herbarium, 5, 151-157.

Roux-López, J. (1964). Estudio morfológico de la epidermis de algunas xerofitas mexicanas (Tesis doctoral). México D.F.: Facultad de Ciencias, Universidad Nacional Autónoma de México.

Rudall, P. (1984). Taxonomic and evolutionary implications of rhizome structure and secondary thickening in Iridaceae. Botanical Gazzete, 45, $524-534$.

Rudall, P. (1989). Stem thickening growth in bulbous Iridaceae. Botanical Gazette, 150, 132-138.

Rudall, P. (1995). New records of secondary thickening in monocotyledons. IAWA Journal, 16, 261-268.

Rudall, P. y Mathew, B. (1993). Leaf anatomy of the bulbous Irises. Botanische Jahrbücher fur Systematik. Pflanzengeschichte und Pflanzengeographie, 115, 63-76.

Rudall, P. J., Chase, M. W., Cutler, D. F., Rusby, J. y de Bruijn, A. (1998). Anatomical and molecular systematics of Asteliaceae and Hypoxidaceae. Botanical Journal of the Linnean Society, 127, 1-42.

Rudall, P. J., Engelman, E. M., Hanson, L. y Chase, M. W. (1998). Systematics of Hemiphylacus, Anemarrhena and Asparagus. Plant Systematics and Evolution, 211, 181-199.

Scatena, V. L., Caetano, F. C. y Oriani, A. (2011). On the taxonomic value of the anatomical structure of vegetative organs and inflorescence axis of Abolboda species (Xyridaceae-Poales). Journal of the Torrey Botanical Society, 138, 381-390.
Shah, G. y Gopal, B. (1970). Structure and development of stomata in the vegetative and floral organs of some Amaryllidaceae. Annals of Botany, $34,737-749$.

Schlittler, J. (1951). Die Gattungen Eustrephus R Br. ex Sims und Geitonoplesium (R. Br.) A. Cunn. Morphologisch-anatomische Studie mit Berucksichtigung der systematischen, nomenklatorischen und arealgeographischen Verhaltrisse. Berichte der Deutschen Botanischen Gesellschaft, 61, 175-239.

Solano, E., Terrazas, T. y González-Becerril, A. (2013). Comparative anatomy of the setm, leaf, and inflorescence basal axis of Polianthes L (Asparagaceae, Agavoideae) species. Feddes Repertorium, 124, 105-115.

Stern, W. L. (1997). Vegetative anatomy of subtribe Orchidinae (Orchidaceae). Botanical Journal of the Linnean Society, 124, 121-136.

Stevenson, D. W. (1980). Radial growth in Beaucarnea recurvata. American Journal of Botany, 67, 476-489.

Tomlinson, P. B. y Zimmermann, M. H. (1969). Vascular anatomy of monocotyledons. Secondary growth an introduction. Journal of the Arnold Arboretum, 50, 159-180.

Verhoek-Williams, S. (1975). A study of the tribe Polianthae (including Manfreda) and revision of Manfreda and Prochnyanthes (Agavaceae) (Tesis doctoral). New York: Cornell University.

Verhoek-Williams, S. (1998). Agavaceae. En K. Kubitzki (Ed.), The families and genera of vascular plants: flowering plants mocotyledons Lilianae (except Orchidaceae), Vol. III. (pp. 60-70). New York: Springer.

Ye, Z. H. (2002). Vascular tissue differentiation and pattern formation in plants. Annual Review of Plant Biology, 53, 183-202. 